\title{
Selective, Retrieval-Independent Disruption of Methamphetamine-Associated Memory by Actin Depolymerization
}

\author{
Erica J. Young ${ }^{1,2}$, Massimiliano Aceti ${ }^{2}$, Erica M. Griggs ${ }^{1,2}$, Rita A. Fuchs ${ }^{3}$, Zachary \\ Zigmond $^{1,2}$, Gavin Rumbaugh ${ }^{2}$, and Courtney A. Miller ${ }^{1,2,{ }^{*}}$ \\ ${ }^{1}$ Department of Metabolism \& Aging, The Scripps Research Institute, Florida. \\ ${ }^{2}$ Department of Neuroscience, The Scripps Research Institute, Florida. \\ ${ }^{3}$ Department of Psychology, University of North Carolina, Chapel Hill
}

\section{Abstract}

Background-Memories associated with drugs of abuse, such as methamphetamine (METH), increase relapse vulnerability to substance use disorder. There is a growing consensus that memory is supported by structural and functional plasticity driven by F-actin polymerization in postsynaptic dendritic spines at excitatory synapses. However, the mechanisms responsible for the long-term maintenance of memories, after consolidation has occurred, are largely unknown.

Methods-Conditioned place preference $(\mathrm{N}=112)$ and context-induced reinstatement of selfadministration $(\mathrm{N}=19)$ were used to assess the role of F-actin polymerization and myosin II, a molecular motor that drives memory-promoting dendritic spine actin polymerization, in the maintenance of METH-associated memories and related structural plasticity.

Results-Memories formed through association with methamphetamine (METH), but not associations with foot shock or food reward, were disrupted by a highly-specific actin cycling inhibitor when infused into the amygdala during the post-consolidation maintenance phase. This selective effect of depolymerization on METH-associated memory was immediate, persistent and did not depend upon retrieval or strength of the association. Inhibition of non-muscle myosin II also resulted in a disruption of METH-associated memory.

Conclusions-Thus, drug-associated memories appear to be actively maintained by a unique form of cycling F-actin driven by myosin II. This finding provides a potential therapeutic approach for the selective treatment of unwanted memories associated with psychiatric disorders

\footnotetext{
C 2013 Society of Biological Psychiatry. Published by Elsevier Inc. All rights reserved.

*Correspondence to: cmiller@scripps.edu.

Publisher's Disclaimer: This is a PDF file of an unedited manuscript that has been accepted for publication. As a service to our customers we are providing this early version of the manuscript. The manuscript will undergo copyediting, typesetting, and review of the resulting proof before it is published in its final citable form. Please note that during the production process errors may be discovered which could affect the content, and all legal disclaimers that apply to the journal pertain.

FINANCIAL DISCLOSURES

The authors report no biomedical financial interest or potential conflict of interest.
} 
that is both selective and does not rely on retrieval of the memory. The results further suggest that memory maintenance depends upon the preservation of polymerized actin.

\section{Keywords}

memory maintenance; addiction; amygdala; structural plasticity; dendritic spine; myosin

A hallmark of memory is its longevity and relative stability $(1,2)$. However, rather than being static after the traditional consolidation period, evidence now points to memories being actively maintained (3-10). Our understanding of protein turnover rates has influenced this notion $(8,11)$. While memories are encoded through functional and structural plasticity, as well as through activation of the upstream epigenetic, transcriptional and signaling events that support plasticity (12-14), the proteins that maintain these changes are themselves transient. This would suggest that the brain and, by extension, long-term memories, are surprisingly dynamic in storage. Additional evidence pointing to the active maintenance of memories comes from the relative ease with which they can be manipulated after consolidation, through extinction and reconsolidation $(3,5,10)$. We and others suspect that these phases of memory largely exist to enable the constant updating and integration of memories (15-17), though they also present a potential therapeutic avenue for weakening aberrant memories associated with psychiatric disorders, such as post-traumatic stress disorder (PTSD) and substance use disorder (SUD) (6, 18-21).

There is a growing consensus that memory is supported by structural and functional plasticity at excitatory synapses (22). Most excitatory synapses are located on dendritic spines, which are small structures that protrude from dendrites and enable input-specific biochemical and electrical isolation of synapses that facilitate signal integration and information storage. Spines undergo volumetric and functional changes that are important for long-term memory $(23,24)$. The actin filaments that comprise the cytoskeleton in dendritic spines are surprisingly dynamic, capable of making rapid changes on the order of seconds (25). Actin polymerization, the process of linking actin monomers (G-actin) into complex, branched filaments (F-actin), is a critical regulator of dendritic spine synapse structure and function $(26,27)$. Indeed, the plasticity that occurs during long-term potentiation (LTP) is dependent upon actin polymerization (28-31). LTP stimulation initiates a multitude of molecular processes that tightly control actin polymerization and the structural enlargement of dendritic spines $(32,33)$. Importantly, memory formation fails when learning-induced F-actin dynamics are disrupted. Further, current studies report that depolymerizing agents are only effective around time of training, as F-actin rapidly stabilizes after learning $(30,34-37)$.

The invasive, drug-associated memories associated with SUD, including associations formed with the widely abused psychostimulant methamphetamine (METH), elicit a motivational state capable of triggering relapse. This occurs through activation of several brain regions, including the brain's emotional memory center, the amygdala (38-43). These long-lasting and extinction-resistant memories can trigger a motivation for the drug even after prolonged drug free periods produced by seemingly successful rehabilitation. Thus, a therapeutic challenge presented by SUD is to disrupt drug-associated memories after they 
have formed. We and others have taken the approach of post-consolidation manipulations focused on the time of retrieval (e.g. blockade of reconsolidation and accelerated extinction) (44-48). In the current study we hypothesized that the actin cytoskeleton supporting structural plasticity may be a target for manipulating the strength of METH-dependent associations after the typical consolidation period. While very little is known about spine plasticity associated with drug-related memories, there is a precedent for drugs of abuse altering F-actin dynamics in the brain. Withdrawal from the psychostimulant cocaine and development of aversive associations with morphine withdrawal both involve actin polymerization (49-51). These suggest that F-actin cycling may mediate unique aspects of memories formed through associations with drugs of abuse.

Conditioned place preference (CPP) and context-induced reinstatement of selfadministration, animal models of contextual reward associations and drug seeking, utilize a circuit that includes the basolateral amygdala complex (BLC; lateral and basolateral) (52-58). Here we investigated the post-consolidation contribution of F-actin dynamics to METH-associated memory and structural plasticity within the BLC through direct disruption of actin polymerization and upstream inhibition of myosin II, a molecular motor that drives memory-promoting dendritic spine actin polymerization (30). We originally hypothesized that interfering with F-actin dynamics in the post-consolidation period would affect the rate at which METH-associated memory extinguished. However, we were surprised to find that actin depolymerization produced an immediate and highly specific loss of METH-associated memory that was independent of retrieval in both rats and mice, indicating a disruption of memory in the maintenance phase. These post-consolidation disruptions to cycling F-actin were ineffective at interfering with the maintenance of other types of associations and reversed dendritic spine density increases produced by METH-associated memory formation. Thus, this unique feature of cycling F-actin renders METH-associated memories susceptible to post-consolidation manipulations and suggests that a general requirement for memory maintenance may be the preservation of polymerization actin.

\section{METHODS AND MATERIALS}

\section{Animals}

Adult male Sprague-Dawley rats (300-350g; Charles River) and Thy1-GFP(m) mice (10wks) were housed under a 12:12 light/dark cycle, with food and water ad libitum. All procedures were performed in accordance with the Scripps Research IACUC. Animals were handled for 3-5 days before behavioral conditioning.

\section{Surgery}

Rats and mice were implanted with $26 \mathrm{G}$ bilateral stainless steel guide cannulae directed at the BLC and rats were implanted with chronic indwelling jugular catheters for intravenous METH self-administration (for additional details and drug infusion rates, see Supplementary Information). 


\section{Drugs}

Methamphetamine hydrochloride (Sigma-Aldrich) was delivered IP at the appropriate dose (rats: $1.0 \mathrm{mg} / \mathrm{kg}$, mice: $2.0 \mathrm{mg} / \mathrm{kg}$ ). Latrunculin A (Calbiochem), an actin depolymerizing agent, was infused at a concentration of $25 \mathrm{ng} / \mu \mathrm{l}$ in $2 \%$ DMSO. Both enantiomers of Blebb ( - =active Blebb, $+=$ =inactive control; Calbiochem), a myosin II inhibitor, were infused at a concentration of $90 \mathrm{ng} / \mu \mathrm{l}$ in $10 \%$ DMSO.

\section{Behavioral Procedures}

Conditioned Place Preference-Animals were trained using an unbiased procedure in an apparatus with three chambers (Med Associates), that differed in terms of visual, tactile and olfactory cues. During the pretest, rats were given free access to the apparatus for $15 \mathrm{~min}$ and the time spent in each chamber was recorded. During training, METH-was given prior to placement in the CS+ chamber for 30min (counterbalanced between chambers within groups). On alternating days, rats were injected with an equivalent volume of $0.9 \%$ saline and confined to the opposite chamber (CS-). This was repeated three times for a total of 6 days, with starting treatment (METH vs saline) also counterbalanced within groups. Testing began $48-72 \mathrm{hrs}$ after the final training session, with free access to the apparatus for $15 \mathrm{~min}$. For additional details regarding modifications for CPP with food reward and in mice, see Supplementary Information.

Auditory Fear Conditioning-Fear conditioning was performed in rats as previously described (37). See Supplementary Information for additional details.

Context-Induced Reinstatement of METH Seeking-The behavioral protocol was performed in rats as previously described and consisted of four phases: (1) training with food pellets to establish lever pressing, (2) METH self-administration in Context A, (3) extinction of lever pressing in Context B and (4) reinstatement in Context A in the absence of METH reward $(58,59)$. For additional details, see Supplementary Information.

\section{Spine Density Analysis}

To determine spine density, 10 dendrite sections per animal, ranging from $20-45 \mu \mathrm{m}$ in length and less than $1 \mu \mathrm{m}$ in width, were selected for analysis from the BLC of Thy1GFP(m) mice following METH or Saline CPP training and intra-BLC vehicle or LatA infusion. For additional details, see Supplementary Information.

\section{Statistical Analysis}

One-way analysis of variance and repeated measures ANOVAs were used to analyze all data, with Fisher's PLSD post hoc tests performed when appropriate.

\section{RESULTS}

\section{Maintenance of METH-associated memory is supported in the amygdala by a dynamic actin cytoskeleton}

For CPP, animals were trained to associate the rewarding effects of METH with the multimodal environmental context in which it was administered. Two days after training that 
produced a lasting memory for the METH-paired context (CS+), rats were given a single intra-BLC infusion of LatA, a highly-specific inhibitor of cycling, but not stable, actin (60). Fifteen minutes after infusion, METH-associated memory was assessed in the absence of the unconditioned stimulus (US), METH reinforcement (Fig. 1A). While vehicle-treated controls displayed a robust METH-associated memory, preferring the CS+ over a salinepaired context (CS-), LatA-treated animals displayed an immediate memory disruption (Fig. 1B). Suspecting that this effect may have been due to a rapid acceleration of extinction by LatA during the 15 minute period of the first test, we examined the Test 1 place preference in five minute blocks. Vehicle-treated animals displayed a place preference throughout the entire test period. However, LatA-treated animals never showed a CS+ preference (Fig. 1C; $0-5 \mathrm{~min}$ : Vehicle- $\mathrm{F}_{(1,9)}=13.03, P<0.005$, LatA- $\mathrm{F}_{(1,8)}=0.06, P>0.05$; 6-10min: Vehicle$\mathrm{F}_{(1,9)}=13.58, P<0.005$, LatA- $\mathrm{F}_{(1,8)}=1.28, P>0.05 ; 11-15 \mathrm{~min}:$ Vehicle $-\mathrm{F}_{(1,9)}=10.29, P<0.05$, LatA: $\left.\mathrm{F}_{(1,8)}=0.74, P>0.05\right)$. Importantly, the LatA-induced disruption of METH-associated memory persisted through subsequent daily tests, despite LatA only being delivered prior to Test 1 (Fig. 1B and S1; Treatment $\times$ Test: $\mathrm{F}_{(5,17)}=2.7, P<0.05$; Vehicle: $\mathrm{F}_{(5,9)}=6.90$, $P<0.0001$; LatA: $\left.\mathrm{F}_{(5,8)}=0.44, P>0.05\right)$. This complete lack of METH-associated memory expression throughout the first test period argues against a LatA-induced acceleration of extinction, as does the necessity of actin polymerization for new learning.

LatA prevents the incorporation of G-actin monomers into dynamic F-actin filaments (60). This suggests that consolidated METH-associated memories may be supported by a constitutively active state of cycling actin, rather than being triggered by the act of memory retrieval. To test this, we gave animals intra-BLC infusions of LatA in the home cage and waited $24 \mathrm{hrs}$ before performing an expression test (Fig. 2A). Indeed, in the same way that a 15 min pre-test infusion did (Fig. 1), home cage LatA treatment disrupted METH-associated memory 24 hrs later (Fig. 2B; Vehicle: $\mathrm{F}_{(1,5)}=13.47 ; P<0.05$; LatA: $\mathrm{F}_{(1,7)}=0.31, P>0.05$ ), indicating that LatA's efficacy does not rely on coincident retrieval of the memory. Rather, it targets maintenance of the memory.

Unlike the impact of actin depolymerization on a METH-associated contextual memory, another BLC-dependent memory, auditory fear $(35,61)$, is known to become insensitive to blockade of polymerization within minutes of learning $(30,37)$, such that pre-test BLC blockade has no effect on the memory $(34,37)$. To further investigate the specificity of this effect on METH-associated memory, we explored the possibility that appetitive memories, in general, are susceptible to actin depolymerization days after training (Fig. 3A). METH $\mathrm{CPP}$ requires just three $\mathrm{CS}+$ pairings to establish a clear place preference (Fig. 1B and 2B). However, we found this was an insufficient number of pairings to produce CPP for sweetened food as the reward (Vehicle: CS- 331.4 $\pm 27.1, \mathrm{CS}+343.6 \pm 26.6, \mathrm{~F}_{(1,6)}=0.06$, $P>0.05$; LatA: CS- 301.4 $\left.\pm 44.9, \mathrm{CS}+343.4 \pm 28.1 \mathrm{~F}_{(1,4)}=0.51, P>0.05\right)$. Therefore, animals were given seven CS+ pairings. Interestingly, unlike an identical memory in which METH was the US, pre-test LatA failed to disrupt the food reward association (Fig. 3B; Vehicle: $\mathrm{F}_{(1,6)}=62.15, P<0.0005$; LatA: $\left.\mathrm{F}_{(1,4)}=8.68, P<0.05\right)$, indicating that a prolonged period of cycling actin is not a general feature of appetitive memories.

Another potential explanation for the selective disruption of METH-associated memory is one of memory strength. That is, perhaps unlike fear and food reward memories, the METH- 
associated memory is weak enough to render it susceptible to disruption by LatA. The failure of three $\mathrm{CS}+$ pairings to produce an association with food reward argues against this. However, to further explore this possibility, we examined LatA's effects on two different, strong METH-associated memories. In the first experiment, animals were given seven, rather than three, $\mathrm{CS}+$ pairings (Fig. 4A). This resulted in a METH-associated memory in vehicle-treated animals of approximately twice the strength of that produced by three CS+ pairings (Fig. 4B and Fig. 2B). Despite this increase in memory strength, post-consolidation LatA completely abolished the place preference (Fig. 4B; Vehicle: $\mathrm{F}_{(1,10)}=16.17, P<0.005$; LatA: $\left.\mathrm{F}_{(1,8)}=0.28, P>0.05\right)$.

Continuing to explore the question of memory strength, as well as the type of memory and translational potential, we next assessed the ability of LatA to disrupt the maintenance of context-induced reinstatement of METH seeking, an animal model of drug seeking/relapse that relies on instrumental learning of a contextual memory $(44,57)$ (Fig. 4C). Rats were trained instrumentally to lever press for METH in a specific context (Context A), producing a robust association between the context and METH over the course of 14 daily, two hour training sessions (Fig. 4D). Rats were then moved to Context B where METH was withheld to extinguish the instrumental response, isolating the impact of context on METH seeking during the subsequent reinstatement sessions in Context A (Fig. 4C). After reaching extinction criterion (Fig. 4D; Phase (training, extinction) $\times$ Lever $\mathrm{F}_{(1,17)}=0.03$; Training Phase: Active $-\mathrm{F}_{(1,17)} 0.02$; Inactive $-\mathrm{F}_{(1,17)}=0.01$; Extinction Phase: Active $-\mathrm{F}_{(1,17)}=0.20$; Inactive $-\mathrm{F}_{(1,17)}=0.0004 ; P>0.05$ for all comparisons), rats were returned to Context $\mathrm{A}$ and reinstatement was assessed by the number of active lever presses in the absence of METH reinforcement. Exposure to the METH-paired context 12 days after the final METH selfadministration session reinstated drug seeking in controls, but not in animals that received intra-BLC LatA infusions (Fig. 4E). As with the METH CPP Pavlovian association, the impact of blocking actin polymerization persisted into a subsequent, LatA-free test of this instrumental memory, without affecting inactive lever pressing (Fig. 4E; Treatment $\times$ Test: $\mathrm{F}_{(3,16)}=5.09, P<0.005$; Reinstatement 1 : Active $-\mathrm{F}_{(1,16)}=7.92, P<0.05$; Inactive $\mathrm{F}_{(1,16)}=2.72, P>0.05$; Reinstatement 2 : Active $-\mathrm{F}_{(1,16)}=4.98, P<0.05$; Inactive $\left.\mathrm{F}_{(1,16)}=0.87, P>0.05\right)$.

Given that intra-BLC actin cycling blockade does not affect the expression of fear or food reward memories, it is unlikely that LatA infusions damage the BLC. To confirm this, we tested the ability of animals that have undergone LatA-induced disruption of METHassociated memory to subsequently learn a BLC-dependent association $(62,63)$. Two weeks after LatA infusion and testing for METH-associated memory (Fig. 4A-B), the same animals were trained for auditory fear conditioning and tested the following day in the absence of LatA (Fig. 5A). Importantly, animals that displayed a previous LatA-induced disruption of METH-associated memory expressed an auditory fear memory equal in strength to previously vehicle-treated controls (Fig. 5B; $\mathrm{F}_{(1,18)}=0.03 ; P>0.05$ ).

Excitatory synapse number increases in the BLC with amphetamine CPP (64). Therefore, given F-actin's critical role in the formation and stabilization of dendritic spines and the importance of structural plasticity to memory, we hypothesized that METH CPP training would produce a similar increase and that LatA's effect on METH-associated memory 
maintenance may stem from a structural disruption within the BLC. To assess this, we investigated changes in dendritic spine density using Thy1-GFP(m) mice that express eGFP in forebrain pyramidal neurons (65). Fortuitously, we observed exquisite labeling within the BLC (Fig. 6A). Similar to the effect of LatA in rats (Fig. 1B, 2D, 4B and 4E), pre-test LatA disrupted the maintenance of METH-associated memory (Fig. 6B-C; Sal CPP+Veh:

$\mathrm{F}_{(1,6)}=2.03, P>0.05$; Sal CPP+LatA: $\mathrm{F}_{(1,6)}=1.15, P>0.05$; METH CPP+Vehicle: $\mathrm{F}_{(1,6)}=7.47$, $P<0.05$; METH CPP+LatA: $\left.\mathrm{F}_{(1,6)}=0.001, P>0.05\right)$. We next analyzed BLC spine density and all dendrites selected for analysis were comparable in width across groups (Fig. S2;

$\left.\mathrm{F}_{(3,16)}=0.23, P>0.05\right)$. Spine density in METH-trained animals increased with CPP training $(P<0.0005)$. Further, pre-test LatA infusion delivered two days after training reduced spine density in METH-paired animals, with no effect on spines under control conditions (Fig. 6D-E; $\mathrm{F}_{(3,24)}=8.89, P<0.0005$; Sal CPP+Veh vs METH CPP+Veh $P<0.0005$, Sal CPP+LatA vs METH CPP+Veh $P<0.0005$, METH CPP+LatA vs METH CPP+Veh $P<0.005)$. A correlation trend between strength of METH-associated memory expression and spine density was observed in vehicle animals, but not in those treated with LatA or saline-trained controls (Fig. 6F).

\section{Nonmuscle myosin II, a trigger of plasticity-inducing F-actin polymerization in dendritic spines, is required for the maintenance of METH-associated memory}

While LatA is a well-studied, highly specific inhibitor of cycling actin (60), our results up to this point have relied upon a single pharmacologic tool. Therefore, to further confirm that maintenance of METH-associated memory is an actin-dependent mechanism, we turned to nonmuscle myosin II, a highly specific molecular motor we have previously demonstrated to be a driver of plasticity and memory-promoting spine actin polymerization (30). Similar to the effect of LatA, intra-BLC infusion of Blebbistatin (Blebb), a specific inhibitor of nonmuscle myosin II motor activity (66), prior to a retrieval test (Fig. 7A) produced an immediate and persistent disruption of METH-associated memory (Fig. 7B; Treatment $\times$ Test 1-2: $\mathrm{F}_{(2,17)}=4.22, P<0.05$; Veh: $\mathrm{F}_{(2,8)}=21.81 ; P<0.0005$; Blebb: $\left.\mathrm{F}_{(2,9)}=0.54 ; P>0.05\right)$.

\section{DISCUSSION}

In this study, we demonstrate that METH-associated memory can be disrupted through direct actin depolymerization or myosin II inhibition days to weeks after consolidation, in the absence of retrieval. This rapid and persistent disruption of a memory by targeting cycling F-actin after consolidation was unexpected. We and others have previously demonstrated that learning triggers a brief window of F-actin dynamics, such that depolymerization at the time of training prevents the consolidation of hippocampus- and amygdala-dependent fear memories (30, 34-37). However, this window of actin cycling closes quickly $(30,37)$, stabilizing the long-term memory. As a result, intra-BLC blockade of F-actin cycling prior to testing fails to disrupt the expression of an auditory fear memory or a food reward place preference (Fig. 3B) $(34,37)$. On the contrary, METH-associated memory is susceptible to immediate and lasting disruption days after training, regardless of memory strength. Further, the disruption 24 hours after home cage delivery of LatA indicates that LatA's efficacy does not rely on coincident retrieval of the memory and cannot be attributed to an effect on reconsolidation or a suppression of memory expression induced 
by residual presence of the compound. It is also worth noting that LatA's inability to disrupt a consolidated food reward memory indicates that the disruption of a METH-associated memory cannot be attributed to a reduced motivation for reward. Taken together, the findings indicate that the actin cytoskeleton supporting a METH-associated memory is perpetually dynamic, rendering it uniquely susceptible to depolymerization during the maintenance phase. This finding adds to a very small literature on memory maintenance mechanisms $(8,9,67-69)$ and is, to our knowledge the first evidence that memories formed through distinct associations can be actively maintained via different molecular substrates. But perhaps most importantly, these results suggest that the actin cytoskeleton may be a target for the selective disruption of consolidated, maladaptive memories, such as those associated with SUD.

\section{The role of F-actin in the maintenance of memory}

Over the past decade, a handful of studies have begun to delve into memory storage mechanisms and there is mounting evidence that memory traces must be actively maintained, even when not in use. For instance, in an elegant series of experiments, Tsien and colleagues demonstrate the necessity of the NR1 subunit of the NMDA receptor for remote fear memory storage (8). In addition, we have previously shown that ongoing DNA methylation is required in the cortex to maintain a remote fear memory (Miller et al., 2010). While the downstream consequences of active DNA methylation have not yet been identified in memory maintenance, we hypothesize that this lasting epigenetic modification enables transcription of the synaptic proteins supporting structural and functional plasticity. A number of other studies have demonstrated that infusion of a peptide suspected of disrupting the activity of the constitutively active protein kinase, PKM $\zeta$, disrupts the maintenance of various forms of consolidated associative memory (70). The specificity of the reagent used to disrupt memory maintenance in the majority of those studies, ZIP, has recently been called into question $(68,69)$. However, while the target responsible for ZIP's efficacy is likely not limited to PKM $\zeta$, memory maintenance studies performed to date collectively indicate that memory traces must be actively maintained. Our current study adds to this growing literature, though the results presented here suggest that the molecular mechanisms maintaining previously consolidated memories can vary with the nature of the association. In the current case, the particular US (e.g. drug vs food reward or foot shock) appears to confer different F-actin states to the memory trace. To our knowledge, this is the first evidence that memories formed through distinct associations can be actively maintained via different molecular substrates.

In addition, the universal, but time-limited efficacy of actin depolymerizing agents on various associative memories at the time of learning would seem to suggest that a general feature of successful memory storage is stabilization of the actin cytoskeleton. Interestingly, both METH-associated memory and fear memory are known to be long-lasting and extinction-resistant. Yet, as demonstrated here, they are supported by different states of Factin, cylcing versus stable. Therefore, an extension of the current results is the inference that a general feature of memory maintenance may not be a stabilized actin cytoskeleton, but rather, a reliance on the simple preservation of F-actin that was polymerized at the time of memory formation. 


\section{Selective disruption of drug-associated memory in the maintenance phase}

Presently, it is clear that memories are formed and supported through changes in the strength of neural connections. However, because memory maintenance mechanisms are so poorly understood, it has been unclear if they are generalized across all forms of memory, or if certain types of memories are maintained through unique mechanisms. This latter possibility is exciting, as it has the potential to provide a means for selective targeting of specific memories, while leaving others intact. Indeed, our data support the latter possibility, perhaps uncovering a strategy to selectively target a class of memories that are associated with psychiatric disorders. Selective disruption of unwanted memories is an emerging approach to the treatment of a variety of psychiatric disorders (19-21). Individuals suffering from SUD or PTSD, for example, seek treatment long after the consolidation window for these unwanted associations has closed. Given the presumed challenge of targeting a specific memory trace during the maintenance phase, we and others have explored alternative strategies. These approaches are primarily focused on accelerating extinction or disrupting reconsolidation of the memory $(19,20,45-48,58)$. Indeed, recent studies have made the promising demonstration that the interactions between extinction and reconsolidation can be exploited to weaken underlying associations in both rodent models and patients $(17,45,71)$. A potential limitation of these strategies is the requirement of memory retrieval and, in the case of reconsolidation manipulations, the risk of simultaneously disrupting other memories inadvertently retrieved during treatment. Further, the brain is strikingly adept at associating seemingly disparate details. In the case of METH abuse, individuals report craving elicited not only by METH paraphernalia (e.g. pipe, torch lighter), but also by the sight of cigarettes, money and gum (72). For these reasons, it may prove difficult to target every drug association and only drug associations in the clinic through reconsolidation and extinction manipulations. Discovery of the unique biology governing the actin cytoskeleton's maintenance of METH-associated memory may enable one to circumvent these challenges.

\section{Myosin II as a means of targeting F-actin cycling}

The concept that myosin II can drive a perpetual form of F-actin dynamics in neurons is well established, as its canonical function is to drive retrograde actin flow in growth cones of developing neurons (73). Within growth cones, myosin II drives the turnover of large Factin bundles by imparting a shearing force on them, resulting in the formation of small actin structures that then passively depolymerize. This process replenishes the pool of free G-actin monomers used to polymerize F-actin at the tip of the growth cone. If myosin II function is lost, the flow of actin stops, and the growth cone collapses. In recent studies, we have demonstrated that synaptic myosin II imparts a similar mechanical force that drives spine F-actin polymerization. This reorganizes the cytoskeleton to support the stable expression of LTP, as well as hippocampus and amygdala-dependent memory $(30,37)$. One candidate mechanism through which F-actin dynamics and myosin II processes may uniquely regulate METH associations is withdrawal-induced dopamine or BDNF. Both are released in the BLC following cocaine self-administration $(74,75)$ and are capable of regulating functional and structural plasticity (76-78). Thus, it is possible that the actin cytoskeleton supporting METH-associated memory initially stabilizes, but is later reactivated upon forced abstinence from METH at the completion of training. This could lead to dopamine or BDNF release in the amygdala and a reactivation of actin cycling, 
rendering the trace susceptible to disruption through depolymerization. While many future studies will be required, the current data indicate that myosin II is indeed regulating a unique and complex system of F-actin dynamics in the amygdala after consolidation of a METHassociated memory. In addition, our finding that actin depolymerization via LatA led to a decrease in spine density in the amygdala of METH-trained animals indicates a potential role for myosin II and actin-mediated dendritic spine growth and maintenance as a candidate for supporting the memory trace.

\section{Supplementary Material}

Refer to Web version on PubMed Central for supplementary material.

\section{Acknowledgments}

This work was funded by grants from the National Institute on Drug Abuse (R00 DA024761 and R01DA034116 to C.A.M.) and National Institute for Neurological Disorders and Stroke (R01NS064079 to G.R.). The authors thank $\mathrm{X}$. Xie for his technical assistance.

\section{REFERENCES}

1. McGaugh JL. Time-dependent processes in memory storage. Science. 1966; 153:1351-1358. [PubMed: 5917768]

2. Muller GE, Pilzecker A. Experimentelle Beiträge zur Lehre vom Gedächtnis. Z Psychol. 1900; 1:1288.

3. Finnie PSB, Nader K. The role of metaplasticity mechanisms in regulating memory destabilization and reconsolidation. Neuroscience \& Biobehavioral Reviews. 2012; 36:1667-1707. [PubMed: 22484475]

4. Nader K, Schafe GE, LeDoux JE. Reply [mdash] Reconsolidation : The labile nature of consolidation theory. Nat Rev Neurosci. 2000; 1:216-219. [PubMed: 11257912]

5. Orsini CA, Maren S. Neural and cellular mechanisms of fear and extinction memory formation. Neuroscience \& Biobehavioral Reviews. 2012; 36:1773-1802. [PubMed: 22230704]

6. Fiorenza NG, Sartor D, Myskiw JC, Izquierdo I. Treatment of fear memories: interactions between extinction and reconsolidation. Anais da Academia Brasileira de Ciências. 2011; 83:1363-1372. [PubMed: 22146964]

7. Medina JH, Bekinschtein P, Cammarota M, Izquierdo I. Do memories consolidate to persist or do they persist to consolidate? Behavioural Brain Research. 2008; 192:61-69. [PubMed: 18374993]

8. Cui Z, Wang H, Tan Y, Zaia KA, Zhang S, Tsien JZ. Inducible and Reversible NR1 Knockout Reveals Crucial Role of the NMDA Receptor in Preserving Remote Memories in the Brain. Neuron. 2004; 41:781-793. [PubMed: 15003177]

9. Miller CA, Gavin CF, White JA, Parrish RR, Honasoge A, Yancey CR, et al. Cortical DNA methylation maintains remote memory. Nat Neurosci. 2010; 13:664-666. [PubMed: 20495557]

10. Dudai Y. The Restless Engram: Consolidations Never End. Annual Review of Neuroscience. 2012; 35:227-247.

11. Roberson ED, Sweatt JD. A Biochemical Blueprint for Long-Term Memory. Learning \& Memory. 1999; 6:381-388. [PubMed: 10509708]

12. Segal M. Dendritic spines and long-term plasticity. Nat Rev Neurosci. 2005; 6:277-284. [PubMed: 15803159]

13. Roth TL, Roth ED, Sweatt JD. Epigenetic regulation of genes in learning and memory. Essays in biochemistry. 2010; 48:263-274. [PubMed: 20822498]

14. Roediger, HL.; Dudai, Y.; Fitzpatrick, SM. Science of Memory: Concepts. 1 ed.. Oxford University Press; New York, New York: 2007. 
15. Halladay LR, Zelikowsky M, Blair HT, Fanselow MS. Reinstatement of extinguished fear by an unextinguished conditional stimulus. Frontiers in Behavioral Neuroscience. 2012:6. [PubMed: 22375108]

16. Jones B, Bukoski E, Nadel L, Fellous J-M. Remaking memories: Reconsolidation updates positively motivated spatial memory in rats. Learning \& Memory. 2012; 19:91-98. [PubMed: 22345494]

17. Monfils M-H, Cowansage KK, Klann E, LeDoux JE. Extinction-Reconsolidation Boundaries: Key to Persistent Attenuation of Fear Memories. Science. 2009; 324:951-955. [PubMed: 19342552]

18. Kiefer, F.; Dinter, C. New Approaches to Addiction Treatment Based on Learning and Memory.. In: Sommer, WH.; Spanagel, R., editors. Behavioral Neurobiology of Alcohol Addiction. Springer Berlin Heidelberg; 2013. p. 671-684.

19. Milton AL, Everitt BJ. The persistence of maladaptive memory: Addiction, drug memories and anti-relapse treatments. Neuroscience \& Biobehavioral Reviews. 2012; 36:1119-1139. [PubMed: 22285426]

20. Torregrossa MM, Corlett PR, Taylor JR. Aberrant learning and memory in addiction. Neurobiology of Learning and Memory. 2011; 96:609-623. [PubMed: 21376820]

21. Parsons RG, Ressler KJ. Implications of memory modulation for post-traumatic stress and fear disorders. Nat Neurosci. 2013; 16:146-153. [PubMed: 23354388]

22. Kasai H, Fukuda M, Watanabe S, Hayashi-Takagi A, Noguchi J. Structural dynamics of dendritic spines in memory and cognition. Trends in Neurosciences. 2010; 33:121-129. [PubMed: 20138375]

23. Yang G, Pan F, Gan W-B. Stably maintained dendritic spines are associated with lifelong memories. Nature. 2009; 462:920-924. [PubMed: 19946265]

24. Lai CSW, Franke TF, Gan W-B. Opposite effects of fear conditioning and extinction on dendritic spine remodelling. Nature. 2012; 483:87-91. [PubMed: 22343895]

25. Star EN, Kwiatkowski DJ, Murthy VN. Rapid turnover of actin in dendritic spines and its regulation by activity. Nat Neurosci. 2002; 5:239-246. [PubMed: 11850630]

26. Kasai H, Matsuzaki M, Noguchi J, Yasumatsu N, Nakahara H. Structure-stability-function relationships of dendritic spines. Trends in Neurosciences. 2003; 26:360-368. [PubMed: 12850432]

27. Smart FM, Halpain S. Regulation of dendritic spine stability. Hippocampus. 2000; 10:542-554. [PubMed: 11075824]

28. Kim C-H, Lisman JE. A Role of Actin Filament in Synaptic Transmission and Long-Term Potentiation. The Journal of Neuroscience. 1999; 19:4314-4324. [PubMed: 10341235]

29. Lin B, Kramár EA, Bi X, Brucher FA, Gall CM, Lynch G. Theta Stimulation Polymerizes Actin in Dendritic Spines of Hippocampus. The Journal of Neuroscience. 2005; 25:2062-2069. [PubMed: 15728846]

30. Rex CS, Gavin CF, Rubio MD, Kramar EA, Chen LY, Jia Y, et al. Myosin IIb Regulates Actin Dynamics during Synaptic Plasticity and Memory Formation. Neuron. 2010; 67:603-617. [PubMed: 20797537]

31. Krucker T, Siggins GR, Halpain S. Dynamic actin filaments are required for stable long-term potentiation (LTP) in area CA1 of the hippocampus. Proceedings of the National Academy of Sciences. 2000; 97:6856-6861.

32. Hotulainen P, Hoogenraad CC. Actin in dendritic spines: connecting dynamics to function. The Journal of Cell Biology. 2010; 189:619-629. [PubMed: 20457765]

33. Lynch G, Rex CS, Gall CM. LTP consolidation: Substrates, explanatory power, and functional significance. Neuropharmacology. 2007; 52:12-23. [PubMed: 16949110]

34. Mantzur L, Joels G, Lamprecht R. Actin polymerization in lateral amygdala is essential for fear memory formation. Neurobiology of Learning and Memory. 2009; 91:85-88. [PubMed: 18812227]

35. Rehberg K, Bergado-Acosta JR, Koch JC, Stork O. Disruption of fear memory consolidation and reconsolidation by actin filament arrest in the basolateral amygdala. Neurobiology of Learning and Memory. 2010; 94:117-126. [PubMed: 20416387] 
36. Fischer A, Sananbenesi F, Schrick C, Spiess J, Radulovic J. Distinct Roles of Hippocampal De Novo Protein Synthesis and Actin Rearrangement in Extinction of Contextual Fear. The Journal of Neuroscience. 2004; 24:1962-1966. [PubMed: 14985438]

37. Gavin CF, Rubio MD, Young E, Miller C, Rumbaugh G. Myosin II motor activity in the lateral amygdala is required for fear memory consolidation. Learning \& Memory. 2012; 19:9-14. [PubMed: 22174310]

38. Jaffe JH. Trivializing dependence. British journal of addiction. 1990; 85:1425-1427. discussion 1429-1431. [PubMed: 2285838]

39. Tiffany ST. A cognitive model of drug urges and drug-use behavior: Role of automatic and nonautomatic processes. Psychological Review. 1990; 97:147-168. [PubMed: 2186423]

40. Robinson TE, Berridge KC. The neural basis of drug craving: an incentive-sensitization theory of addiction. Brain research Brain research reviews. 1993; 18:247-291. [PubMed: 8401595]

41. Kosten TR, Scanley BE, Tucker KA, Oliveto A, Prince C, Sinha R, et al. Cue-Induced Brain Activity Changes and Relapse in Cocaine-Dependent Patients. Neuropsychopharmacology. 2005; 31:644-650. [PubMed: 16123763]

42. Childress AR, Mozley PD, McElgin W, Fitzgerald J, Reivich M, O'Brien CP. Limbic activation during cue-induced cocaine craving. The American journal of psychiatry. 1999; 156:11-18. [PubMed: 9892292]

43. Grant S, London ED, Newlin DB, Villemagne VL, Liu X, Contoreggi C, et al. Activation of memory circuits during cue-elicited cocaine craving. Proceedings of the National Academy of Sciences. 1996; 93:12040-12045.

44. Wells AM, Arguello AA, Xie X, Blanton MA, Lasseter HC, Reittinger AM, et al. Extracellular Signal-regulated Kinase in the Basolateral Amygdala, but not the Nucleus Accumbens Core, is Critical for Context-response-cocaine Memory Reconsolidation in Rats.

Neuropsychopharmacology. 2012

45. Xue Y-X, Luo Y-X, Wu P, Shi H-S, Xue L-F, Chen C, et al. A Memory Retrieval-Extinction Procedure to Prevent Drug Craving and Relapse. Science. 2012; 336:241-245. [PubMed: 22499948]

46. Miller CA, Marshall JF. Molecular Substrates for Retrieval and Reconsolidation of CocaineAssociated Contextual Memory. Neuron. 2005; 47:873-884. [PubMed: 16157281]

47. Lee JLC, Di Ciano P, Thomas KL, Everitt BJ. Disrupting Reconsolidation of Drug Memories Reduces Cocaine-Seeking Behavior. Neuron. 2005; 47:795-801. [PubMed: 16157275]

48. Malvaez M, Sanchis-Segura C, Vo D, Lattal KM, Wood MA. Modulation of Chromatin Modification Facilitates Extinction of Cocaine-Induced Conditioned Place Preference. Biological Psychiatry. 2010; 67:36-43. [PubMed: 19765687]

49. Hou Y-Y, Lu B, Li M, Liu Y, Chen J, Chi Z-Q, et al. Involvement of Actin Rearrangements within the Amygdala and the Dorsal Hippocampus in Aversive Memories of Drug Withdrawal in Acute Morphine-Dependent Rats. The Journal of Neuroscience. 2009; 29:12244-12254. [PubMed: 19793983]

50. Liu Y, Zhou Q-X, Hou Y-Y, Lu B, Yu C, Chen J, et al. Actin Polymerization-Dependent Increase in Synaptic Arc/Arg3.1 Expression in the Amygdala Is Crucial for the Expression of Aversive Memory Associated with Drug Withdrawal. The Journal of Neuroscience. 2012; 32:12005-12017. [PubMed: 22933785]

51. Toda S, Shen H-W, Peters J, Cagle S, Kalivas PW. Cocaine Increases Actin Cycling: Effects in the Reinstatement Model of Drug Seeking. The Journal of Neuroscience. 2006; 26:1579-1587. [PubMed: 16452681]

52. Everitt BJ, Morris KA, O'Brien A, Robbins TW. The basolateral amygdala-ventral striatal system and conditioned place preference: Further evidence of limbic-striatal interactions underlying reward-related processes. Neuroscience. 1991; 42:1-18. [PubMed: 1830641]

53. Hiroi N, White $\mathrm{N}$. The lateral nucleus of the amygdala mediates expression of the amphetamineproduced conditioned place preference. The Journal of Neuroscience. 1991; 11:2107-2116. [PubMed: 2066777] 
54. Brown EE, Fibiger HC. Differential effects of excitotoxic lesions of the amygdala on cocaineinduced conditioned locomotion and conditioned place preference. Psychopharmacology. 1993; 113:123-130. [PubMed: 7862818]

55. Miller CA, Marshall JF. Altered Fos expression in neural pathways underlying cue-elicited drug seeking in the rat. European Journal of Neuroscience. 2005; 21:1385-1393. [PubMed: 15813948]

56. Miller CA, Marshall JF. Altered Prelimbic Cortex Output during Cue-Elicited Drug Seeking. The Journal of Neuroscience. 2004; 24:6889-6897. [PubMed: 15295023]

57. Fuchs RA, Evans KA, Ledford CC, Parker MP, Case JM, Mehta RH, et al. The Role of the Dorsomedial Prefrontal Cortex, Basolateral Amygdala, and Dorsal Hippocampus in Contextual Reinstatement of Cocaine Seeking in Rats. Neuropsychopharmacology. 2004; 30:296-309. [PubMed: 15483559]

58. Lasseter HC, Wells AM, Xie X, Fuchs RA. Interaction of the Basolateral Amygdala and Orbitofrontal Cortex is Critical for Drug Context-Induced Reinstatement of Cocaine-Seeking Behavior in Rats. Neuropsychopharmacology. 2011; 36:711-720. [PubMed: 21124303]

59. Reichel CM, Ramsey LA, Schwendt M, McGinty JF, See RE. Methamphetamine-induced changes in the object recognition memory circuit. Neuropharmacology. 2012; 62:1119-1126. [PubMed: 22115899]

60. Morton WM, Ayscough KR, McLaughlin PJ. Latrunculin alters the actin-monomer subunit interface to prevent polymerization. Nat Cell Biol. 2000; 2:376-378. [PubMed: 10854330]

61. LeDoux J, Cicchetti P, Xagoraris A, Romanski L. The lateral amygdaloid nucleus: sensory interface of the amygdala in fear conditioning. The Journal of Neuroscience. 1990; 10:1062-1069. [PubMed: 2329367]

62. Rodrigues SM, Schafe GE, LeDoux JE. Molecular Mechanisms Underlying Emotional Learning and Memory in the Lateral Amygdala. Neuron. 2004; 44:75-91. [PubMed: 15450161]

63. Sierra-Mercado D, Padilla-Coreano N, Quirk GJ. Dissociable Roles of Prelimbic and Infralimbic Cortices, Ventral Hippocampus, and Basolateral Amygdala in the Expression and Extinction of Conditioned Fear. Neuropsychopharmacology. 2011; 36:529-538. [PubMed: 20962768]

64. Rademacher DJ, Rosenkranz JA, Morshedi MM, Sullivan EM, Meredith GE. AmphetamineAssociated Contextual Learning Is Accompanied by Structural and Functional Plasticity in the Basolateral Amygdala. The Journal of Neuroscience. 2010; 30:4676-4686. [PubMed: 20357118]

65. Feng G, Mellor RH, Bernstein M, Keller-Peck C, Nguyen QT, Wallace M, et al. Imaging Neuronal Subsets in Transgenic Mice Expressing Multiple Spectral Variants of GFP. Neuron. 2000; 28:4151. [PubMed: 11086982]

66. Kovács M, Tóth J, Hetényi C, Málnási-Csizmadia A, Sellers JR. Mechanism of Blebbistatin Inhibition of Myosin II. Journal of Biological Chemistry. 2004; 279:35557-35563. [PubMed: 15205456]

67. Pastalkova E, Serrano P, Pinkhasova D, Wallace E, Fenton AA, Sacktor TC. Storage of Spatial Information by the Maintenance Mechanism of LTP. Science. 2006; 313:1141-1144. [PubMed: 16931766]

68. Volk LJ, Bachman JL, Johnson R, Yu Y, Huganir RL. PKM-[zgr] is not required for hippocampal synaptic plasticity, learning and memory. Nature. 2013; 493:420-423. [PubMed: 23283174]

69. Lee AM, Kanter BR, Wang D, Lim JP, Zou ME, Qiu C, et al. Prkcz null mice show normal learning and memory. Nature. 2013; 493:416-419. [PubMed: 23283171]

70. Sacktor TC. How does PKM $\zeta$ maintain long-term memory? Nat Rev Neurosci. 2011; 12:9-15. [PubMed: 21119699]

71. Schiller D, Monfils M-H, Raio CM, Johnson DC, LeDoux JE, Phelps EA. Preventing the return of fear in humans using reconsolidation update mechanisms. Nature. 2010; 463:49-53. [PubMed: 20010606]

72. Tolliver BK, McRae-Clark AL, Saladin M, Price KL, Simpson AN, DeSantis SM, et al. Determinants of Cue-Elicited Craving and Physiologic Reactivity in MethamphetamineDependent Subjects in the Laboratory. The American Journal of Drug and Alcohol Abuse. 2010; 36:106-113. [PubMed: 20337507]

73. Medeiros NA, Burnette DT, Forscher P. Myosin II functions in actin-bundle turnover in neuronal growth cones. Nat Cell Biol. 2006; 8:216-226. 
74. Grimm JW, Lu L, Hayashi T, Hope BT, Su T-P, Shaham Y. Time-Dependent Increases in BrainDerived Neurotrophic Factor Protein Levels within the Mesolimbic Dopamine System after Withdrawal from Cocaine: Implications for Incubation of Cocaine Craving. The Journal of Neuroscience. 2003; 23:742-747. [PubMed: 12574402]

75. Tran-Nguyen LTL, Fuchs RA, Coffey GP, Baker DA, Odell LE, Neisewander JL. Time-Dependent Changes in Cocaine-Seeking Behavior and Extracellular Dopamine Levels in the Amygdala during Cocaine Withdrawal. Neuropsychopharmacology. 1998; 19:48-59. [PubMed: 9608576]

76. Higley MJ, Sabatini BL. Competitive regulation of synaptic Ca2+ influx by D2 dopamine and A2A adenosine receptors. Nat Neurosci. 2010; 13:958-966. [PubMed: 20601948]

77. Rex CS, Lin C-Y, Kramár EA, Chen LY, Gall CM, Lynch G. Brain-Derived Neurotrophic Factor Promotes Long-Term Potentiation-Related Cytoskeletal Changes in Adult Hippocampus. The Journal of Neuroscience. 2007; 27:3017-3029. [PubMed: 17360925]

78. Shimada A, Mason CA, Morrison ME. TrkB Signaling Modulates Spine Density and Morphology Independent of Dendrite Structure in Cultured Neonatal Purkinje Cells. The Journal of Neuroscience. 1998; 18:8559-8570. [PubMed: 9786964] 

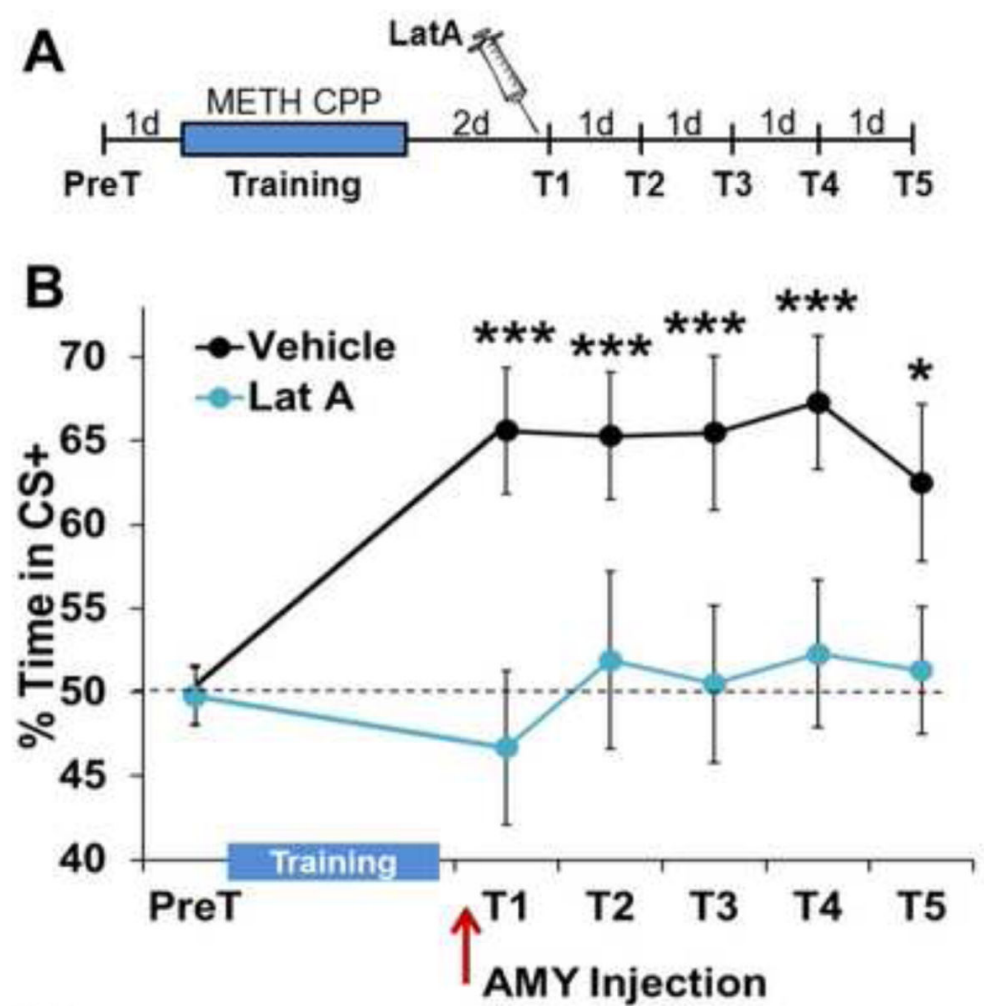

C

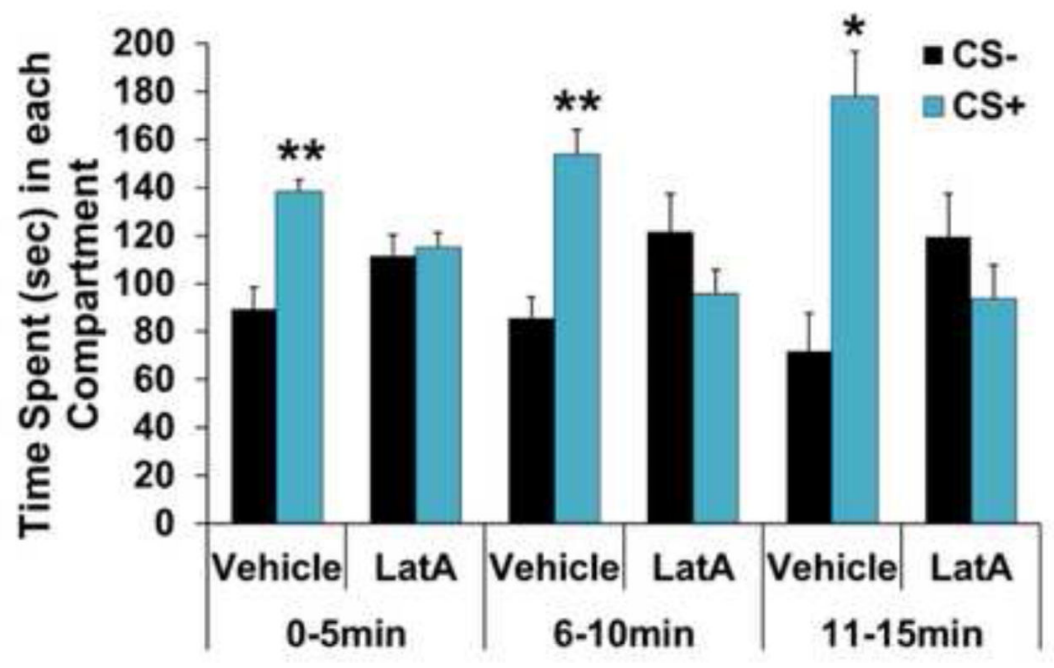

Figure 1.

METH-associated memory is disrupted by actin depolymerization two days after consolidation. (A) Schematic of experimental design for testing METH-associated memory. (B) Intra-BLC blockade of F-actin cycling by LatA prior to Test 1 (T1) produces a persistent disruption of METH-associated memory (Vehicle $n=10$, LatA $n=9$ ). (C) Intra-BLC LatA disrupts METH-associated memory throughout the first preference test, shown in five minute blocks. Error bars represent SEM. 

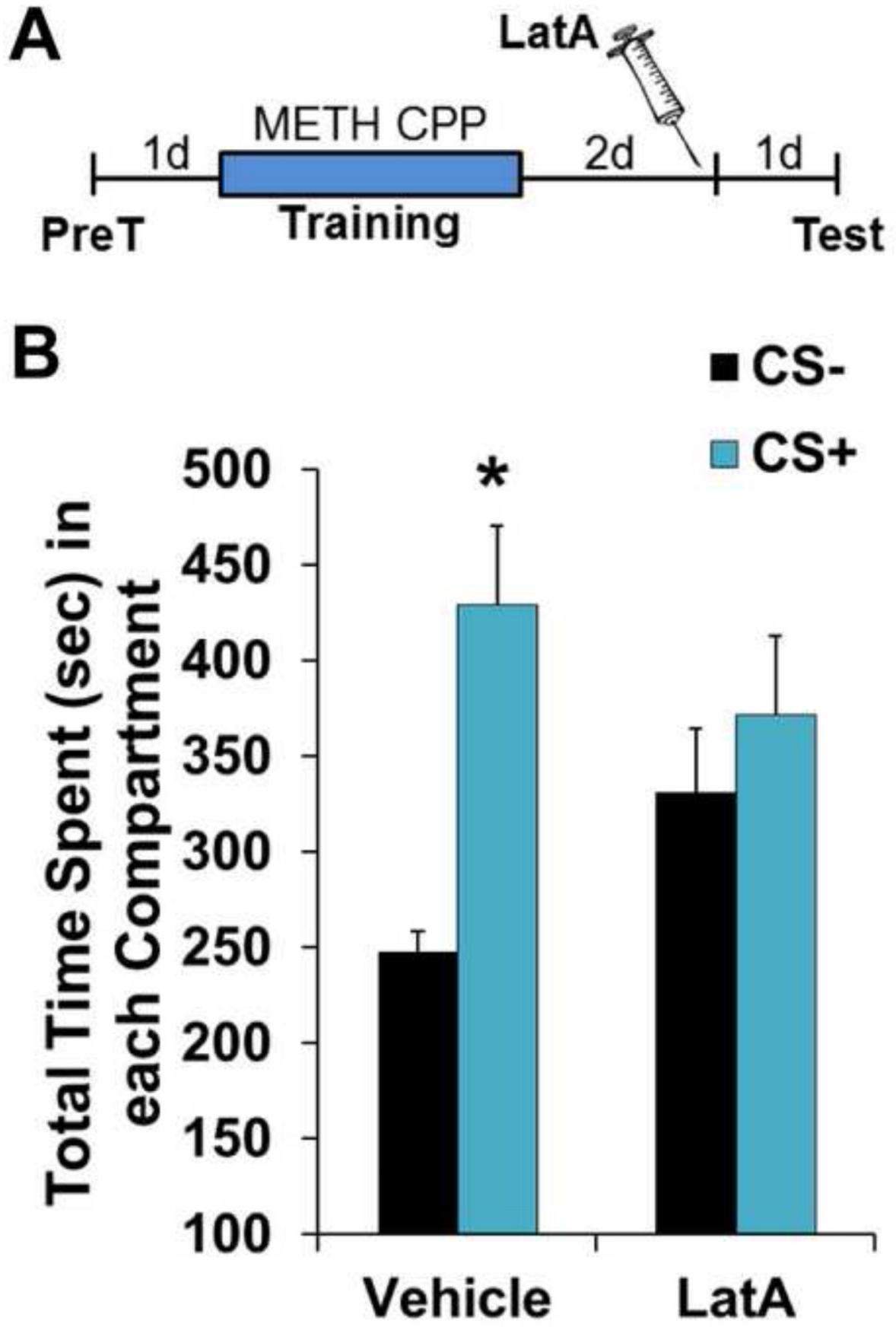

Figure 2.

Disruption of METH-associated memory does not require coincident retrieval. (A) Schematic of experimental design for testing METH-associated memory 24 hours after LatA infusion. (B) Intra-BLC LatA disrupts METH-associated memory $24 \mathrm{hrs}$ after infusion (Vehicle $n=6$, LatA $n=8$ ). Error bars represent SEM. 


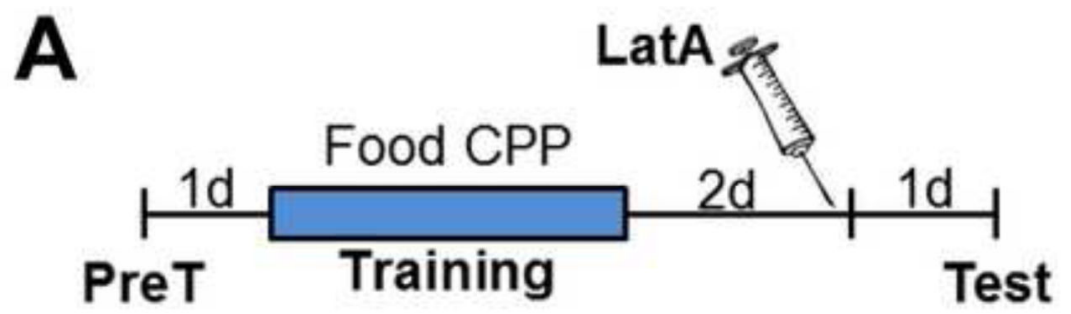

B
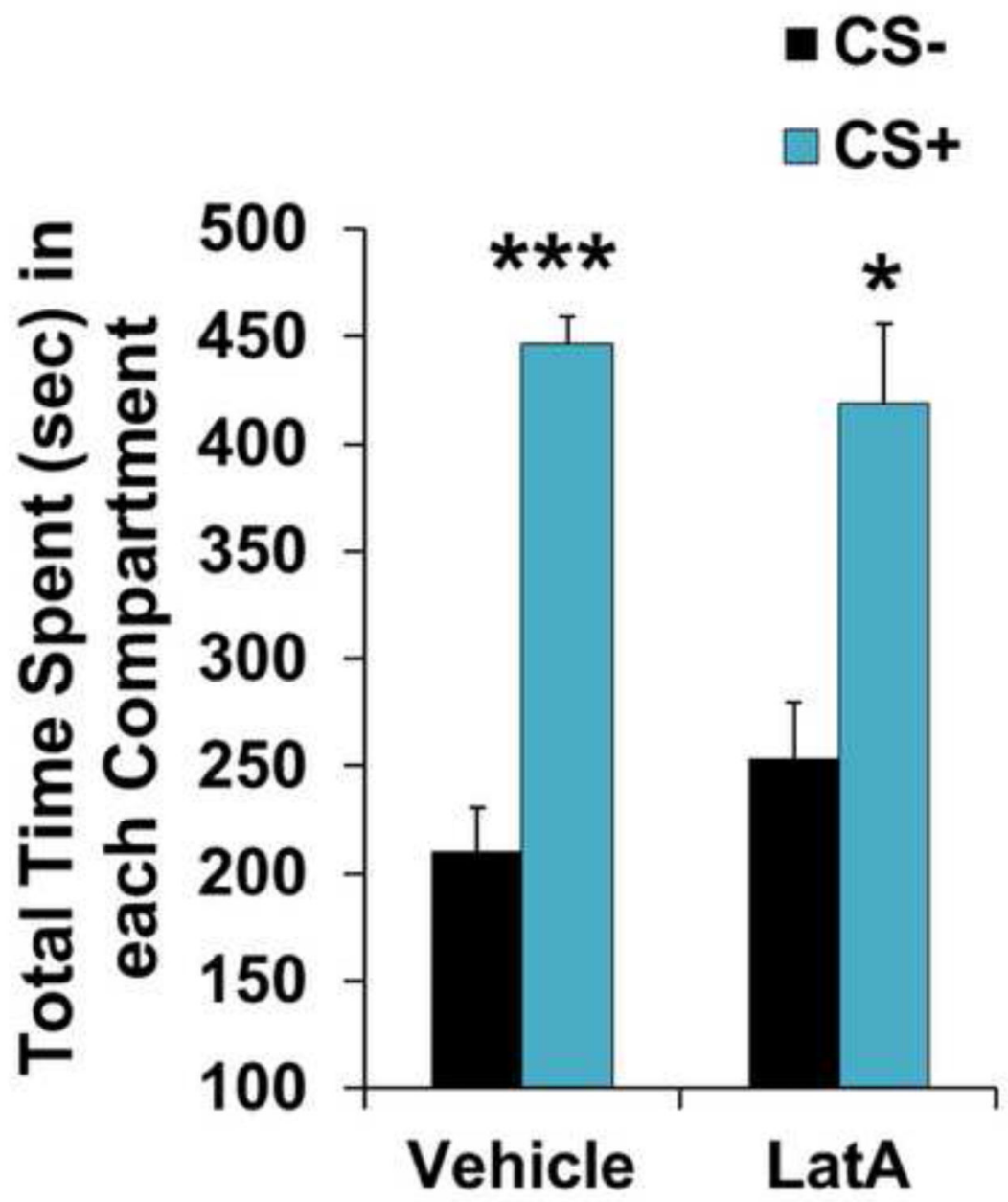

Figure 3.

Disruption of memory maintenance by F-actin depolymerization is specific to METH associations. (A) Schematic of experimental design for test of food reward memory. (B) Intra-BLC LatA has no effect on a place preference memory for food reward (Vehicle $n=7$, LatA $n=5$ ). Error bars represent SEM. 


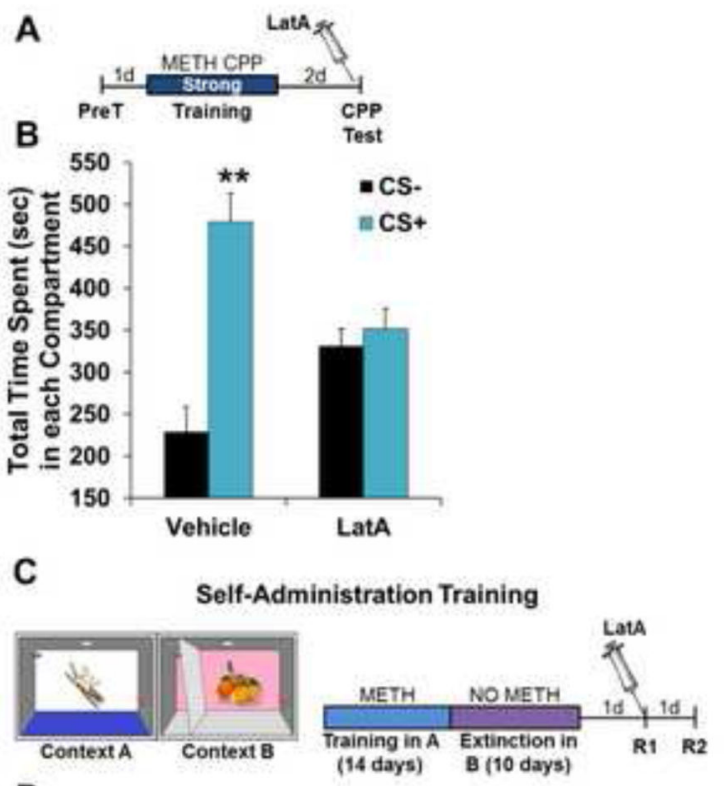

D

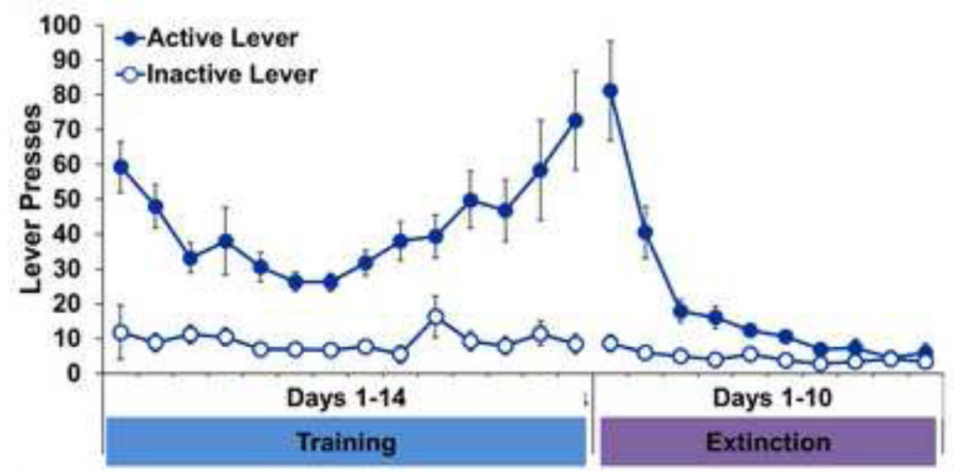

E

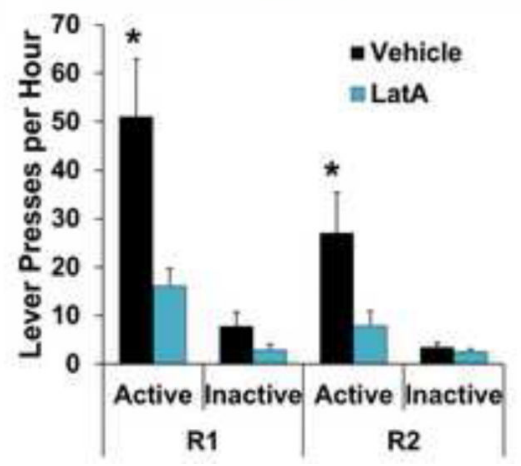

Figure 4.

Disruption of METH-associated memory by F-actin depolymerization does not depend on memory strength or type of learning. (A) Schematic of experimental design for LatAinduced disruption of METH-associated memory following a strong Pavlovian training protocol. (B) Intra-BLC LatA disrupts METH-associated memory following strong training (Vehicle $n=11$, LatA $n=9$ ). (C) Schematic of experimental design for context induced reinstatement of instrumental METH seeking. (D) Association between active lever with METH reinforcement in Context A and subsequent extinction of active lever pressing in 
Context B. (E) Intra-BLC LatA treatment prior to Reinstatement test 1 (R1) produces a persistent disruption of context-induced METH seeking (Vehicle $n=9$, LatA $n=10$ ). Error bars represent SEM. 

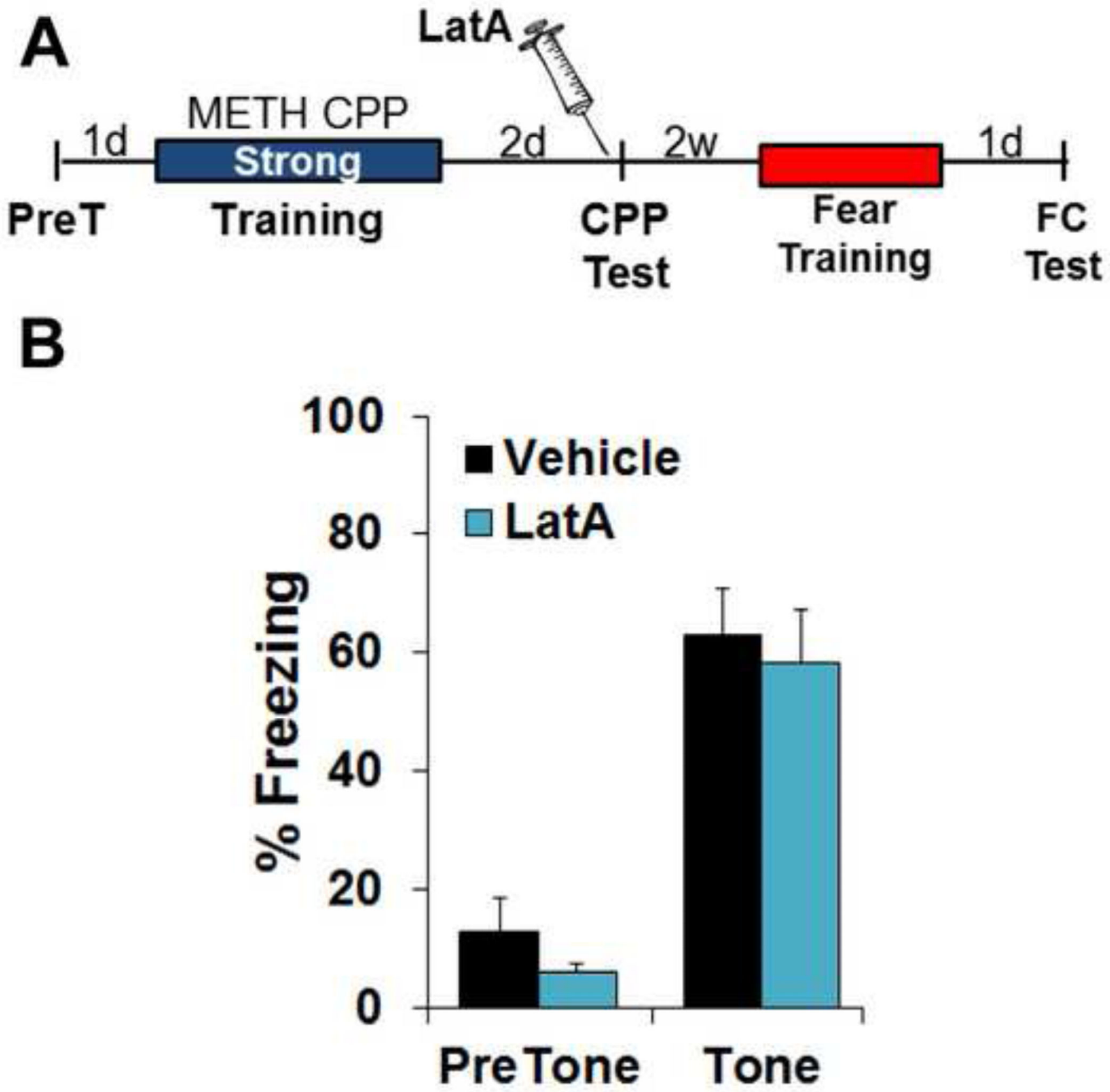

Figure 5.

Disruption of METH-associated memory by F-actin depolymerization does not influence future learning. (A) Schematic of experimental design for auditory fear conditioning following training and subsequent disruption of METH-associated memory (see Figure 4AB). (B) Previous disruption of METH-associated memory by intra-BLC LatA has no effect on subsequent auditory fear learning (see Fig. 4 legend for $n$ 's). Error bars represent SEM. 
A

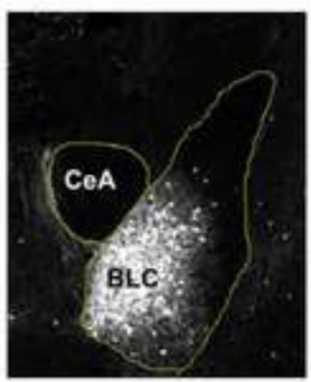

B

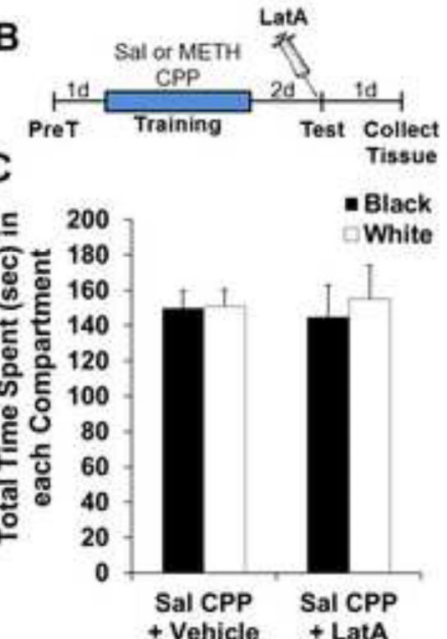

E

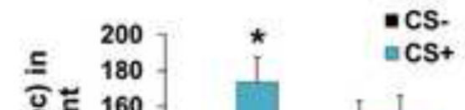

D
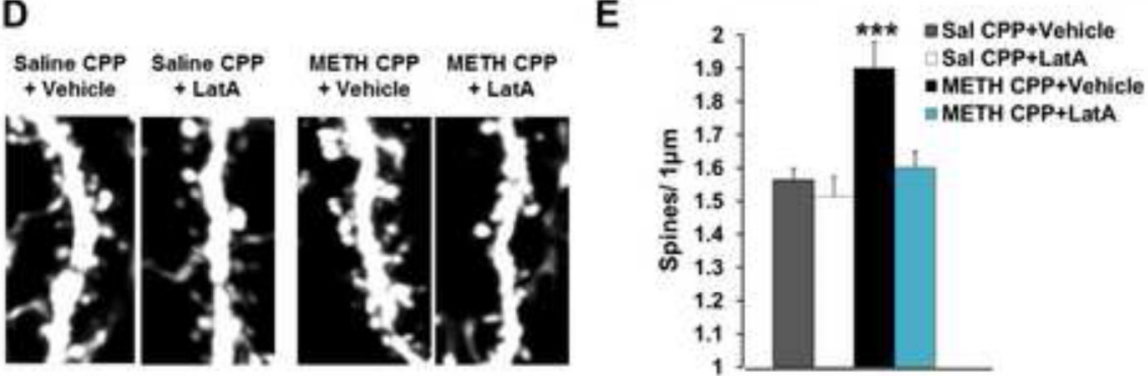

$\mathbf{F}$
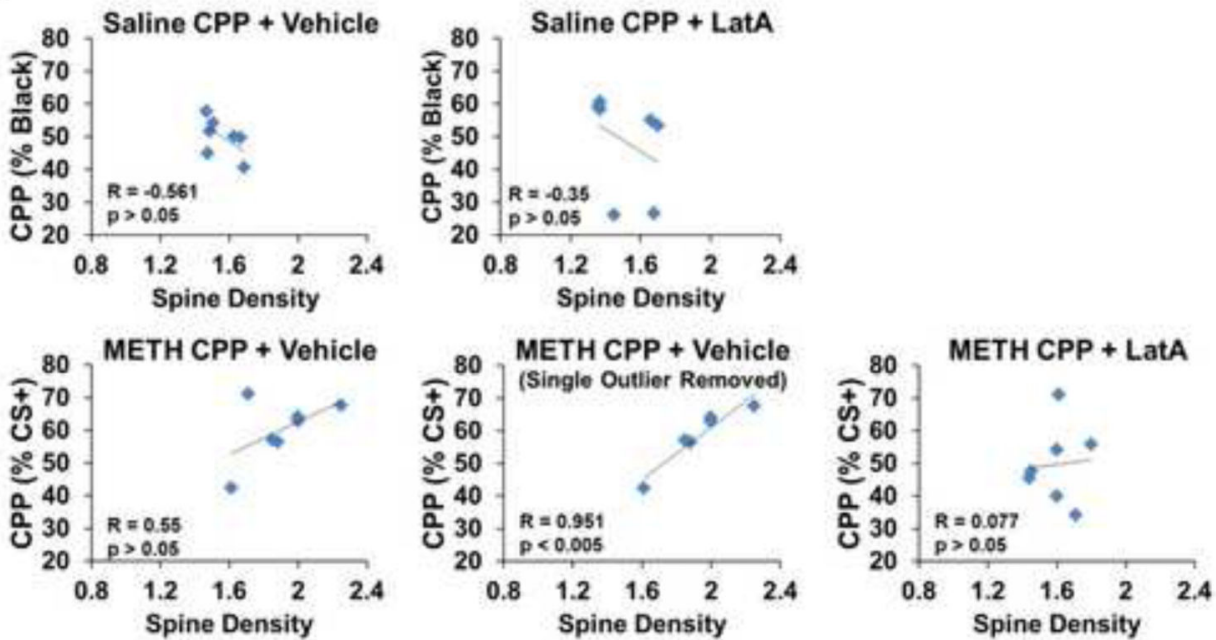

Figure 6.

The spine density increase associated with METH CPP is reversed with memory disruption by F-actin depolymerization. (A) Representative image of eGFP expression in the BLC of Thy1-GFP(m) mice. (B) Schematic of experimental design. (C) Intra-BLC LatA disrupts METH-associated memory in Thy1-GFP(m) mice (right panel), but has no effect on behavior in mice trained with saline on both sides of the CPP apparatus (left panel) ( $n=7$ per group). (D) Representative images of BLC dendritic spines from Thy1-GFP(m) mice after CPP training with saline or METH, followed by intra-BLC vehicle or LatA treatment. (E) 
METH-associated memory was accompanied by an increase in BLC spine density that was reversed by F-actin depolymerization. (F) Effect of intra-BLC LatA on correlations between memory performance and spine density. Error bars represent SEM. 

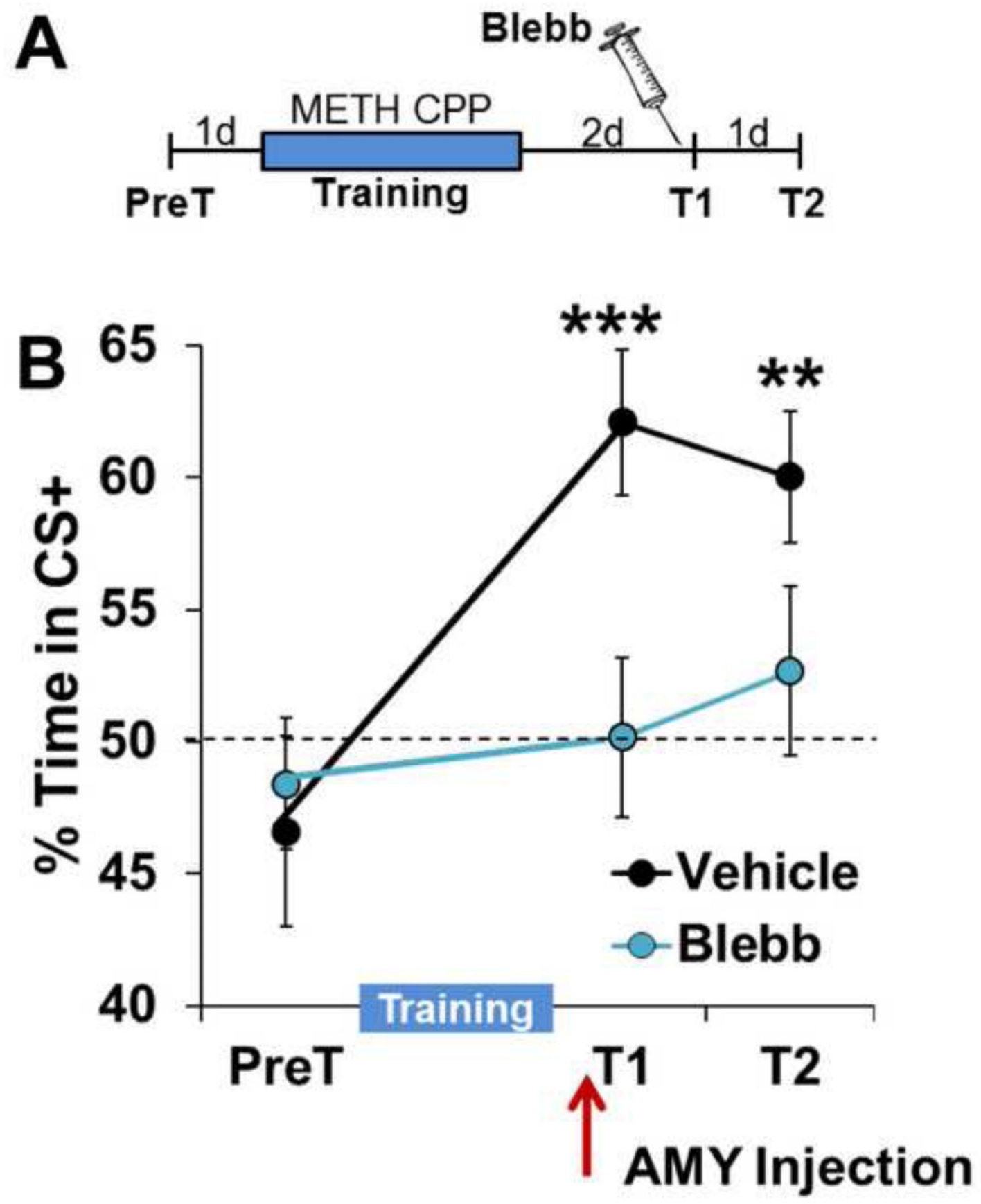

Figure 7.

Intra-BLC inhibition of nonmuscle myosin II, a polymerizer of dendritic spine F-actin, disrupts METH-associated memory. (A) Schematic of experimental design. (B) Intra-BLC Blebb disrupts METH-associated memory (Vehicle $n=9$, Blebb $n=10$ ). Error bars represent SEM. 